\title{
Stability and crystal structures of iron carbides: A comparison between the semi-empirical modified embedded atom method and quantum-mechanical DFT calculations
}

\author{
C. M. Fang,,${ }^{1,2, *}$ M. A. van Huis,,${ }^{1,3}$ B. J. Thijsse, ${ }^{4}$ and H. W. Zandbergen ${ }^{2}$ \\ ${ }^{1}$ Materials Innovation Institute (M2I), Mekelweg 2, 2628 CD Delft, The Netherlands \\ ${ }^{2}$ Kavli Institute of Nanoscience, Delft University of Technology, Lorentzweg 1, 2628 CJ Delft, The Netherlands \\ ${ }^{3}$ EMAT, University of Antwerp, Groenenborgerlaan 171, 2020 Antwerp, Belgium \\ ${ }^{4}$ Department of Materials Science and Engineering, Delft University of Technology, Mekelweg 2, 2628 CD Delft, The Netherlands
}

(Received 7 November 2011; published 29 February 2012)

\begin{abstract}
Iron carbides play a crucial role in steel manufacturing and processing and to a large extent determine the physical properties of steel products. The modified embedded atom method (MEAM) in combination with Lee's Fe-C potential is a good candidate for molecular dynamics simulations on larger Fe-C systems. Here, we investigate the stability and crystal structures of pure iron and binary iron carbides using MEAM and compare them with the experimental data and quantum-mechanical density functional theory calculations. The analysis shows that the Fe-C potential gives reasonable results for the relative stability of iron and iron carbides. The performance of MEAM for the prediction of the potential energy and the calculated lattice parameters at elevated temperature for pure iron phases and cementite are investigated as well. The conclusion is that Lee's MEAM $\mathrm{Fe}-\mathrm{C}$ potential provides a promising basis for further molecular dynamics simulations of $\mathrm{Fe}-\mathrm{C}$ alloys and steels at lower temperatures (up to $800 \mathrm{~K}$ ).
\end{abstract}

DOI: 10.1103/PhysRevB.85.054116

PACS number(s): 75.50.Bb, 64.60.My, 71.15.Nc, 61.50.Lt

\section{INTRODUCTION}

Carbon exists in steels as interstitial atoms in ferrite, austenite, and martensite phases. It is also present in iron carbide phases, as precipitates in a ferrite matrix or in pearlitetype or bainite-type microstructures. ${ }^{1-4}$ The iron carbides are of crucial importance in the design of the material properties of steels and Fe alloys. ${ }^{1-6}$ Good examples are the so-called transformation-induced plasticity (TRIP) steels that are a promising group of cold formable steels that combine a very high ductility with high strength. ${ }^{7-9}$ The TRIP steels are now used in a few applications in the body in white of European and Japanese automobile industry. ${ }^{9,10}$ By means of scanning electron microscopy (SEM) and transmission electron microscopy (TEM), many investigations were performed on the phase characterization and the related microstructures of industrial TRIP and TRIP-assisted multiphase steels. ${ }^{7-14}$ In addition, computational simulations have proven to be very useful for investigation of $\mathrm{FeC}$ phases in steels. Parameter-free first-principles approaches have been employed, but they were applied only to small systems due to the computational limits. ${ }^{15-22}$ For large systems, atomistic simulation methods, such as the pair-potential approach (PPA), ${ }^{23,24}$ the embedded atomic method (EAM), ${ }^{25-31}$ and the recently adopted modified embedded atom method (MEAM) ${ }^{32-34}$ are very valid. The main uncertainty in the large-scale simulations is the model describing interactions between atoms. ${ }^{35}$ Recently, Lee published a new $\mathrm{Fe}-\mathrm{C}$ potential within the MEAM formalism. ${ }^{36}$ This new Fe-C potential has been applied for pure iron, interstitial $\mathrm{C}$ in $\mathrm{Fe}$, as well as several iron carbides. ${ }^{37-40}$ However, there is no systematic investigation of the applicability of Lee's MEAM potential to iron carbides, ${ }^{36-40}$ which play a crucial role in steel manufacturing and processing. In this paper, we summarize our recent work in pure iron and iron carbides phases using the MEAM approach. A comparison of the MEAM calculations with the first-principles density functional theory (DFT) within the generalized gradient approximation (GGA) and the conventional local density approximation (LDA) approaches, as well as with the available experimental values in literature, is presented. These results are helpful for understanding the relative stability of iron and iron carbides and, in particular, for sensible analysis of large-scale molecular dynamics simulations of $\mathrm{Fe}$ and $\mathrm{Fe}-\mathrm{C}$ systems.

\section{CAlCulation DETAILS}

\section{A. Formation energies}

The formation energy $(\Delta E)$ of an iron carbide $\left(\mathrm{Fe}_{\mathrm{n}} \mathrm{C}_{\mathrm{m}}\right)$ from the pure solids of the elements ( $\alpha$ phase and graphite) can be described as:

$$
\Delta E=E\left(\mathrm{Fe}_{\mathrm{n}} \mathrm{C}_{\mathrm{m}}\right)-[\mathrm{n} E(\mathrm{Fe})+\mathrm{m} E(\mathrm{C})] .
$$

To assess the relative stability of different iron carbides, we use the formation energy per atom $\left(\Delta E_{f}\right)$ :

$$
\Delta E_{f}=\Delta E /(\mathrm{n}+\mathrm{m}) .
$$

The energy $\Delta E_{C}$ to insert $\mathrm{C}$ in $\mathrm{Fe}$ sublattices to form $\mathrm{Fe}_{\mathrm{n}} \mathrm{C}$ is defined as:

$$
\Delta E_{C}=E\left(\mathrm{Fe}_{\mathrm{n}} \mathrm{C}\right)-[\mathrm{n} E(\mathrm{Fe})+E(\mathrm{C})]
$$

Positive values of $\Delta E_{C}\left(\Delta E_{f}\right)$ indicate that the $\mathrm{Fe}$ sublattices with interstital $\mathrm{C}$ atoms or the iron carbides are metastable, while negative values indicate genuine stability of the systems, relative to the elemental solids (ferrite and graphite). At a temperature of $0 \mathrm{~K}$ and a pressure of $0 \mathrm{~Pa}$, the enthalpy difference is equal to the energy difference, that is $\Delta H\left(\mathrm{Fe}_{\mathrm{n}} \mathrm{C}_{\mathrm{m}}\right)=\Delta E\left(\mathrm{Fe}_{\mathrm{n}} \mathrm{C}_{\mathrm{m}}\right)$, when we ignore the zero-point vibration contribution. 


\section{B. Lee's Fe-C MEAM potential}

In 2006, Lee published his work on the MEAM potential for the $\mathrm{Fe}-\mathrm{C}$ system, including the effects of second nearest neighbors. ${ }^{36}$ In the MEAM, the total energy of an Fe-C system is given in the following form:

$$
E=\sum_{\mathrm{i}} F_{i}\left(\rho_{i}\right)+1 / 2 \sum_{i} \sum_{j} \phi_{i j}\left(R_{i j}\right),
$$

where $F_{i}\left(\rho_{i}\right)$ is the embedding function for an atom $i$ embedded in a background electron density $\rho_{i}$, and $\phi_{i j}\left(R_{i j}\right)$ is the pair potential for the interaction between atoms $i$ and $j$ separated by a distance of $R_{i j}$. The background electron density at each atomic site is computed by combining several partial electron density terms for different angular contributions with weight factors. In the Lee MEAM potentials, the second nearest neighbors interactions were taken into account by adjusting the screening parameters. Details of the MEAM formalism and the parameters for the $\mathrm{Fe}-\mathrm{C}$ system were described in Refs. 33-36.

Lee's potential has been integrated into the molecular dynamics code CAMELION, ${ }^{31,41}$ which was used in this work. All simulations have been performed using a barostat and a thermostat of the Berendsen type. ${ }^{42}$ Unless mentioned otherwise, results are given for $0 \mathrm{~K}$ (after rapid cooling) and 0 bar. During energy minimization, the relative atomic positions were left unconstrained in the unit cells for the binary iron carbide phases, except for the simple structures, such as $\mathrm{NaCl}$-type, CsCl-type, and ZnS-type structures of FeC, where the formation energies and lattice parameters were obtained by their energy-volume relationships.

\section{DFT calculations}

All the DFT calculations were carried out using the firstprinciples' Vienna $a b$ initio Simulation Program (VASP) ${ }^{43-45}$ employing density functional theory (DFT) within the projector-augmented wave (PAW) method. ${ }^{46,47}$ Both the spinpolarized GGA formulated by Perdew, Burke, and Ernzerhof $(\mathrm{PBE})^{48}$ and the conventional spin-polarized $\mathrm{LDA}^{49}$ were employed for the exchange and correlation energy terms. The cutoff energy of the wave functions was $500.0 \mathrm{eV}$. The cutoff energy of the augmentation functions was about $644.8 \mathrm{eV}$. The electronic wave functions were sampled on dense grids, e.g. a $12 \times 12 \times 12$ grid with $84 k$ points or a $24 \times 24 \times 24$ grid with $364 k$ points in the irreducible Brillouin zone (BZ) of $\theta-\mathrm{Fe}_{3} \mathrm{C}$ or of $\alpha-\mathrm{Fe}$, respectively, using the Monkhorst and Pack method. ${ }^{50}$ Structural optimizations were performed for both lattice parameters and coordinates of atoms. The tests of $k$-mesh and cutoff energies showed a good convergence $(<1 \mathrm{meV} /$ atom $)$.

\section{RESULTS}

\section{A. Classification of iron carbides}

There are four solid phases for pure iron: ferrite or $\alpha$-Fe (bcc), which is the ground state at ambient conditions; austenite or $\gamma$-Fe (fcc), which is stable in the temperature range between 1185 to $1667 \mathrm{~K}$; the high-temperature phase $\delta$-Fe (bcc) (stable from $1667 \mathrm{~K}$ to the melting point $1811 \mathrm{~K}$ ); and the high-pressure phase $\varepsilon$-Fe (hcp). The $\delta$-Fe phase is isostructural with $\alpha$-Fe (bcc). Their difference lies in magnetism: the ground state of $\alpha$-Fe (bcc) is ferromagnetic (FM) while $\delta$-Fe (bcc) is nonmagnetic (NM). ${ }^{51}$ Table I shows the MEAM results for bcc-Fe and fcc-Fe compared with those calculated with DFT-LDA and DFT-GGA. As expected, the MEAM lattice parameters and formation energies reproduce the former MEAM calculations. ${ }^{36}$ The DFT-GGA correctly predicts that the FM bcc-Fe phase is the ground state, while the DFT-LDA predicts the wrong ground state [nonmagnetic, (NM-)Fcc]. The MEAM lattice parameters agree with the experimental values much better than those from DFT-GGA and DFT-LDA. For bcc-Fe, this was to be expected because the MEAM potential was explicitly fitted to the lattice parameter. All three computational methods confirm that the ground state of iron is the ferrite phase, while the $\gamma$ - and $\varepsilon$-Fe (not shown) phases are less stable (Table I). That agrees with former DFT-GGA calculations. ${ }^{51-56}$

There are several phases for $\mathrm{C}$, and at ambient conditions, the stable phase is graphite. However, it is difficult to perform MEAM calculations for graphite due to the interlayer Van der Waals interaction, which is not included in the MEAM potential. Experiments showed that graphite is about $17 \mathrm{meV} / \mathrm{C}$ more stable than the diamond phase. ${ }^{18,57}$ Therefore, the MEAM energy for graphite is obtained from that of the diamond phase after this correction. The calculated lattice parameter for diamond is $a=3.558 \AA$, in agreement with the experimental value.

TABLE I. Calculated results for the iron phases using Lee's Fe-C MEAM potential compared with the DFT-GGA and DFT-LDA calculations as well as with the experimental values. The deviations (\%) of the calculated lattice parameters from the experimental values are included $(\mathrm{FM}=$ ferromagnetic, $\mathrm{NM}=$ nonmagnetic).

\begin{tabular}{lcc}
\hline \hline & bcc Fe & fcc Fe \\
\hline MEAM & $a=2.864(-0.1 \%)$ & $a=3.604(+0.5 \%)$ \\
Lattice parameters $(\AA)$ & 0.0 & 0.062 \\
$\Delta E \mathrm{eV} / \mathrm{Fe}$ & & $a=3.372(-6.3 \%)$ \\
DFT-LDA & $a=2.751(-4.0 \%)$ & $-0.066(\mathrm{NM})$ \\
Lattice parameters $(\AA)$ & $0.0(\mathrm{FM})$ & $a=3.477(-3.1 \%)$ \\
$\Delta E \mathrm{eV} / \mathrm{Fe}$ & $a=2.833(-0.9 \%)$ & $0.060(\mathrm{NM})$ \\
DFT-GGA & $0.0(\mathrm{FM})$ & $a=3.585$ \\
Lattice parameters $(\AA)$ & $a=2.866$ & \\
$\Delta E \mathrm{eV} / \mathrm{Fe}$ & & \\
Experimental lattice parameters $(\AA)$ & & \\
\hline \hline
\end{tabular}


TABLE II. Calculated lattice parameters at $0 \mathrm{~K}$ using Lee's Fe-C potential within the MEAM approach compared with the DFT-GGA and DFT-LDA methods and compared with experimental values (Tetra = tetragonal, Orth = orthorhombic).

\begin{tabular}{|c|c|c|c|c|c|}
\hline Formula & Lattice & $\begin{array}{l}\text { MEAM lattice } \\
\text { parameters }(\AA)\end{array}$ & $\begin{array}{l}\text { DFT-GGA lattice } \\
\text { parameters }(\AA)\end{array}$ & $\begin{array}{l}\text { DFT-LDA lattice } \\
\text { parameters }(\AA)\end{array}$ & $\begin{array}{c}\text { Experimental lattice } \\
\text { parameters }(\AA)\end{array}$ \\
\hline \multicolumn{6}{|l|}{ bcc based } \\
\hline \multirow[t]{3}{*}{$\alpha^{\prime}-\mathrm{Fe}_{16} \mathrm{C}$} & Tetra & $a=5.616$ & $a=5.6382$ & $a=5.457$ & \\
\hline & & $c=6.228$ & $c=6.0757$ & $c=5.875$ & \\
\hline & & $c / a=1.109$ & $c / a=1.078$ & $c / a=1.076$ & \\
\hline \multirow{3}{*}{$\alpha^{\prime}-\mathrm{Fe}_{16} \mathrm{C}_{2}$} & Tetra & $a=5.697$ & $a=5.6553$ & $a=5.4721$ & \\
\hline & & $c=6.309$ & $c=6.2624$ & $c=6.1182$ & \\
\hline & & $c / a=1.109$ & $c / a=1.107$ & $c / a=1.118$ & \\
\hline \multirow[t]{3}{*}{$\alpha^{\prime \prime}-\mathrm{Fe}_{3} \mathrm{C}_{2}$} & Orth & $a=5.464$ & $a=5.471$ & $a=5.428$ & \\
\hline & & $b=3.189$ & $b=2.747$ & $b=2.688$ & \\
\hline & & $c=10.518$ & $c=11.202$ & $c=10.805$ & \\
\hline \multicolumn{6}{|l|}{ fcc based } \\
\hline$\gamma^{\prime}-\mathrm{FeC}(\mathrm{NaCl}-)$ & fcc & $a=4.096$ & $a=4.001$ & $a=3.923$ & \\
\hline$\gamma^{\prime \prime}-\mathrm{FeC}(\mathrm{CsCl}-)$ & fcc & $a=4.096$ & $a=4.001$ & $a=3.923$ & \\
\hline$\gamma^{\prime \prime}-\mathrm{FeC}(\mathrm{ZnS}-)$ & fcc & $a=4.325$ & $a=4.2541$ & $a=4.1775$ & \\
\hline$\gamma^{\prime}-\mathrm{Fe}_{4} \mathrm{C}$ & Cubic & $a=3.923(+1.2 \%)$ & $a=3.767(-2.8 \%)$ & $a=3.643(-6.4 \%)$ & $a=3.875$ \\
\hline$\gamma^{\prime}-\mathrm{Fe}_{8} \mathrm{C}$ & Cubic & $a=7.403(1.1 \%)$ & $a=7.247(-1.0 \%)$ & $a=6.957(-5.0 \%)$ & $a=7.323$ \\
\hline \multicolumn{6}{|l|}{ hcp family } \\
\hline \multirow[t]{3}{*}{$\theta-\mathrm{Fe}_{3} \mathrm{C}$} & Orth & $a=5.165(+1.0 \%)$ & $a=5.037(-0.9 \%)$ & $a=4.841(-6.7 \%)$ & $a=5.082$ \\
\hline & & $b=6.277(-5.5 \%)$ & $b=6.720(-0.2 \%)$ & $b=6.516(-3.2 \%)$ & $b=6.733$ \\
\hline & & $c=4.674(+3.0 \%)$ & $c=4.482(-0.3 \%)$ & $c=4.329(-4.1 \%)$ & $c=4.514$ \\
\hline \multirow[t]{3}{*}{$\mathrm{o}-\mathrm{Fe}_{7} \mathrm{C}_{3}$} & Orth & $a=4.851(+6.9 \%)$ & $a=4.517(-0.5 \%)$ & $a=4.396(-3.2 \%)$ & $a=4.540$ \\
\hline & & $b=6.684(-2.8 \%)$ & $b=6.856(-0.3 \%)$ & $b=6.669(-3.1 \%)$ & $a=6.879$ \\
\hline & & $c=11.447(-4.1 \%)$ & $c=11.733(-1.7 \%)$ & $c=11.409(-4.4 \%)$ & $c=11.940$ \\
\hline \multirow[t]{3}{*}{$\eta-\mathrm{Fe}_{2} \mathrm{C}$} & Orth & $a=4.342(-7.7 \%)$ & $a=4.707(+0.1 \%)$ & $a=4.245(-9.8 \%)$ & $a=4.704$ \\
\hline & & $b=4.419(+2.9 \%)$ & $b=4.280(0.3 \%)$ & $b=4.356(+1.4 \%)$ & $b=4.295$ \\
\hline & & $c=2.854(+0.8 \%)$ & $c=2.824(-0.2 \%)$ & $c=2.794(-1.3 \%)$ & $c=2.830$ \\
\hline \multirow{3}{*}{$\zeta-\mathrm{Fe}_{2} \mathrm{C}$} & Orth & $a=4.280$ & $a=4.2997$ & $a=4.255$ & \\
\hline & Pbcn & $b=5.456$ & $b=5.4810$ & $b=5.293$ & \\
\hline & & $c=4.829$ & $c=4.8511$ & $c=4.693$ & \\
\hline
\end{tabular}

Table II lists structural information of important iron carbides in steels, ${ }^{4,18-21}$ according to MEAM and DFT calculations and experimental data. These iron carbides include three different types according to their Fe sublattices. ${ }^{4,58,59}$ The bcc family contains the so far unanalyzed $\alpha^{\prime}-\mathrm{Fe}_{16} \mathrm{C}$, $\alpha^{\prime}-\mathrm{Fe}_{16} \mathrm{C}_{2}$, and $\alpha^{\prime \prime}-\mathrm{Fe}_{3} \mathrm{C}_{2}$ phases [see Figs. 1(a) and 1(b)], which consist of bcc- Fe sublattices with $\mathrm{C}$ interstitial atoms occupying the octahedral sites. The second type is the fcc family, of which the structures are based on the $\gamma$-Fe sublattice with $\mathrm{C}$ at the octahedral or tetrahedral sites [Figs. 1(c) and 1(d)]. The third is the $\varepsilon$-family [Figs. 1(e) and 1(f)] with members $\eta$ - $\mathrm{Fe}_{2} \mathrm{C}$ and $\theta-\mathrm{Fe}_{3} \mathrm{C}$, which play important roles in manufacturing processes, as well as in the microstructures and physical properties of $\mathrm{Fe}-\mathrm{C}$ steels. Details of the results will be discussed in Subsec. C.

\section{B. Formation energies of iron carbides}

Figure 2 shows the formation energies obtained from the calculations. There are few experimental values of high accuracy due to the difficulties associated with the preparation of homogeneous samples. Overall, the DFT-GGA results agree best with the experimental values, while the DFT-LDA overestimates the stability. The MEAM results are in between. Below, we discuss the calculation results in detail.
In the martensite phase, as shown by Domain et al., C atoms occupy the octahedral sites. ${ }^{4,56,58}$ The MEAM calculations show that for dilute $\mathrm{C}$ in $\alpha-\mathrm{Fe}$, the $\mathrm{C}$ solution energy is $1.17 \mathrm{eV} / \mathrm{C}$, in good agreement with Lee's calculations. ${ }^{36}$ Figure 1 shows the schematic structures for $\alpha^{\prime}-\mathrm{Fe}_{16} \mathrm{C}, \alpha^{\prime}-\mathrm{Fe}_{16} \mathrm{C}_{2}$ [both in Fig. 1(a)], and $\alpha^{\prime \prime}-\mathrm{Fe}_{3} \mathrm{C}_{2}$ [Fig. 1(b)]. The calculated formation energy for $\alpha^{\prime}-\mathrm{Fe}_{16} \mathrm{C}$ phase by the MEAM approach is $0.92 \mathrm{eV} / \mathrm{C}$, which is smaller than the solution energy of dilute $\mathrm{C}$ in ferrite $(1.17 \mathrm{eV} / \mathrm{C})$. This value, $0.92 \mathrm{eV} / \mathrm{C}$, is about twice the value found using the DFT-GGA approach $(0.45 \mathrm{eV} / \mathrm{C})$. However, it is close to the value $(0.89 \mathrm{eV} / \mathrm{C})$ from the DFT-LDA calculations. Please note that the experimental values for dilute $\mathrm{C}$ in ferrite have a scattering range (from about 0.4 to $1.2 \mathrm{eV}) .^{36,56}$ The MEAM calculations showed for $\alpha^{\prime}-\mathrm{Fe}_{16} \mathrm{C}_{2}$ the formation energy is lowered to about $0.81 \mathrm{eV} / \mathrm{C}$ from $0.92 \mathrm{eV} / \mathrm{C}$ (for $\alpha^{\prime}-\mathrm{Fe}_{16} \mathrm{C}$ ), with the same trend for DFT, as shown in Fig. 2. The phase of the highest carbon concentration, $\alpha^{\prime \prime}-\mathrm{Fe}_{3} \mathrm{C}_{2}$, is calculated to be slightly favored with respect to the elemental solids (ferrite and graphite) by the MEAM approach. The DFT-GGA calculations show that $\alpha^{\prime \prime}-\mathrm{Fe}_{3} \mathrm{C}_{2}$ is metastable with a formation energy of $135 \mathrm{meV} /$ atom. However, the MEAM result for this carbide is not far from the DFT-LDA result, about $4 \mathrm{meV} /$ atom difference (Fig. 2). 
(a)

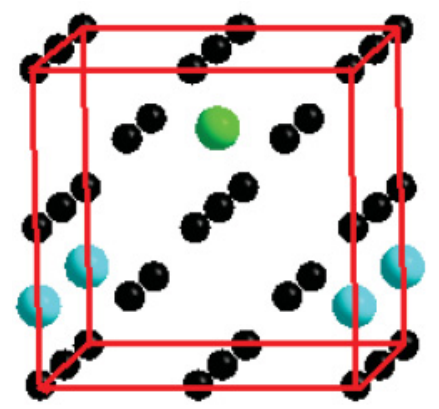

(b)

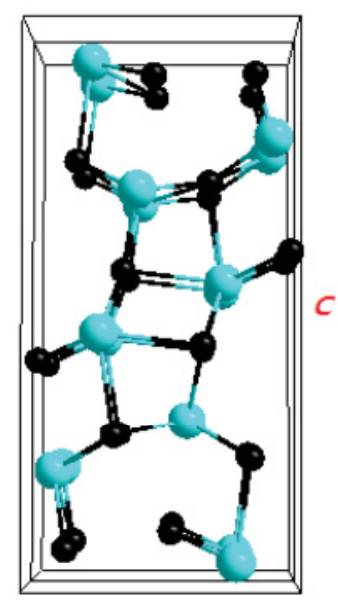

$a$

(c)

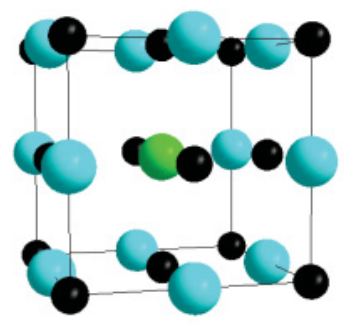

(e)

(d)

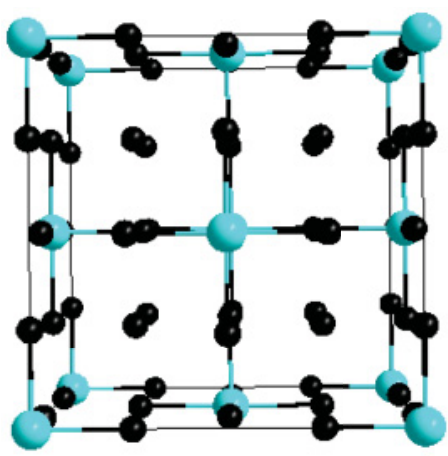

(f)

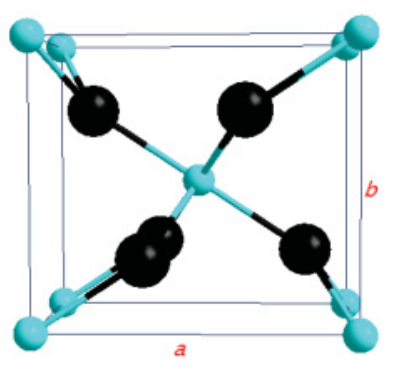

FIG. 1. (Color online) Schematic structures of the iron carbides from the bcc family: (a) $\alpha^{\prime}-\mathrm{Fe}_{16} \mathrm{C}, \alpha^{\prime}-\mathrm{Fe}_{16} \mathrm{C}_{2}$ and (b) $\alpha^{\prime \prime}-\mathrm{Fe}_{3} \mathrm{C}_{2}$; from the fcc family: (c) $\gamma^{\prime}-\mathrm{FeC}$ with $\mathrm{NaCl}$-type structure and (d) $\gamma^{\prime}-\mathrm{Fe}_{4} \mathrm{C}$; from the hcp family: (e) the cementite phase $\theta-\mathrm{Fe}_{3} \mathrm{C}$ and (f) the Hägg phase $\eta$ - $\mathrm{Fe}_{2} \mathrm{C}$. The small black spheres represent $\mathrm{Fe}$ atoms, big green/medium gray spheres $\mathrm{C}$ atoms. The blue/light gray spheres in (a) represent another occupied $\mathrm{C}$ site to form $\alpha^{\prime}-\mathrm{Fe}_{16} \mathrm{C}_{2}$. In (c) the small black and the green/gray spheres in the $\gamma^{\prime}-\mathrm{Fe}_{4} \mathrm{C}$ structure indicate the $4 \mathrm{Fe}$ and $1 \mathrm{C}$ atom positions, respectively. In the $\mathrm{FeC}$ structure, again, blue (light gray)/green (medium gray) spheres indicate $\mathrm{C}$ atoms and black spheres $\mathrm{Fe}$ atoms. Lattice parameters $(a, b, c)$ are indicated in panels (b), (e), and (f).

For the fcc family, we start from $\gamma^{\prime}-\mathrm{FeC}$, having the NaCl-type structure [Fig. 1(c)]. The calculated (MEAM) formation energy is $405 \mathrm{meV} /$ atom, which is much smaller than the GGA result. However, this value is close to the LDA results (415 meV/atom), as shown in Fig. 2. All



FIG. 2. (Color online) The calculated formation energies for the iron carbides using different approaches. The crystal structures are displayed in Fig. 1, the calculated lattice parameters are listed in Table II. The different colors represent the calculated results by means of MEAM (green/light gray), DFT-GGA (red/dark gray), DFT-LDA (blue/medium gray) and experimental values (black). ${ }^{61}$ The filled spheres represent for the bcc family, filled squares the fcc family, and filled diamonds the hcp family (see Table II).

calculations for $\gamma^{\prime}-\mathrm{Fe}_{4} \mathrm{C}$ give positive formation energies. For $\gamma^{\prime}-\mathrm{Fe}_{8} \mathrm{C}$, the MEAM formation energy is $85 \mathrm{meV} /$ atom, close to that by DFT-GGA (110 meV/atom). In contrast, the DFT-LDA predicts this phase as being too stable $\left(\Delta E_{f}=\right.$ $-40 \mathrm{meV} /$ atom), considering that this phase has never been observed experimentally.

The members of the hop family, such as $\theta-\mathrm{Fe}_{3} \mathrm{C}$ (the cementite phase) and $\eta-\mathrm{Fe}_{2} \mathrm{C}$ (the Hägg phase) [Fig. 1(e)-1(f)], play a crucial role in the steel manufacturing processes. ${ }^{1-5,20}$ As shown in Fig. 2, the MEAM calculations show that the order of stability for the most important hep phases is (from high stability to lower): $\eta-\mathrm{Fe}_{2} \mathrm{C}>0-\mathrm{Fe}_{7} \mathrm{C}_{3}>\theta-\mathrm{Fe}_{3} \mathrm{C}$, the same order as the experimental order. Meanwhile, DFTGGA showed that in the three hcp phases, o- $\mathrm{Fe}_{7} \mathrm{C}_{3}$ is the least stable, while DFT-LDA calculations show that $\mathrm{o}-\mathrm{Fe}_{7} \mathrm{C}_{3}$ has the lowest formation energy. Our MEAM calculations give a moderate stability $(\sim-15 \mathrm{meV} /$ atom $)$ for $\theta-\mathrm{Fe}_{3} \mathrm{C}$, the cementite phase (Fig. 2). The DFT-LDA calculations produce an even higher stability $\left(-84 \mathrm{meV} /\right.$ atom) for $\theta-\mathrm{Fe}_{3} \mathrm{C}$ cementite. The MEAM calculations show that $\eta-\mathrm{Fe}_{2} \mathrm{C}$ is more stable than $\zeta-\mathrm{Fe}_{2} \mathrm{C}$. This agrees with the DFT-GGA calculations, as well as with the experimental observation that $\eta-\mathrm{Fe}_{2} \mathrm{C}$ occurs frequently in tempering of quenched $\mathrm{Fe}-\mathrm{C}$ steels, while the $\zeta$-phase has never been observed. Please note that both $\eta-\mathrm{Fe}_{2} \mathrm{C}$ and $\zeta-\mathrm{Fe}_{2} \mathrm{C}$ have similar $\mathrm{Fe}$ sublattices. The major difference is the ordering of $\mathrm{C}$ atoms. ${ }^{4,19,20,59}$ In $\eta$ - $\mathrm{Fe}_{2} \mathrm{C}$, along the $c$ axis the carbon atoms form $\mathrm{C}-\mathrm{C}$ bonds with lengths of about $2.8 \AA$, while in $\zeta-\mathrm{Fe}_{2} \mathrm{C}$, the $\mathrm{C}$ atoms form zigzagged chains with longer C-C bond lengths., ${ }^{4,20}$ Meanwhile, the DFT-LDA calculations also predict wrong formation energies for all the hcp iron carbides as shown in Fig. 2. 


\section{Lattice parameters of iron carbides}

From Table II, we see that the MEAM lattice parameters of the three novel members of the bcc family $\left(\alpha^{\prime}, \alpha^{\prime}, \alpha^{\prime \prime}\right)$ are in good agreement with the DFT-GGA calculations. However, the calculated $c / a$ ratio (1.11) of $\alpha^{\prime}-\mathrm{Fe}_{16} \mathrm{C}$ using the MEAM method is almost the same as that of $\alpha^{\prime}-\mathrm{Fe}_{16} \mathrm{C}_{2}$, whereas the $c / a$ ratio of $\mathrm{Fe}_{16} \mathrm{C}$ (1.08) increases to 1.11 for $\alpha^{\prime}-\mathrm{Fe}_{16} \mathrm{C}_{2}$ using the DFT methods.

For $\gamma^{\prime}-\mathrm{FeC}$ with the NaCl-type structure [Fig. 1(c)], the calculated lattice parameter is $4.10 \AA$, in agreement with Lee's calculations. ${ }^{36}$ Our calculated lattice parameter is slightly larger than the GGA $(4.00 \AA)$ and LDA (3.92 $\AA$ ) results.

For $\gamma^{\prime}-\mathrm{Fe}_{4} \mathrm{C}$ and $\gamma^{\prime}-\mathrm{Fe}_{8} \mathrm{C}$, the MEAM calculations reproduce the experimental lattice parameters well, within $1.2 \%$ (Table II). In comparison, the DFT-GGA underestimates the experimental values by about 3\%, and the DFT-LDA by about $6.0 \%$.

For the well-known hcp family members, the MEAM calculations give significant deviations of the lattice parameters from the experimental values, particularly for the $b$ axis in $\theta-\mathrm{Fe}_{3} \mathrm{C}$, the $a$ axis in $\mathrm{o}-\mathrm{Fe}_{7} \mathrm{C}_{3}$, and $\eta-\mathrm{Fe}_{2} \mathrm{C}$ deviation about $+7 \%$. Comparatively, the lattice parameters from the DFTGGA calculations agree well with the experimental values (within 1.7\%). The DFT-LDA calculations, however, provide even worse agreements with the experimental values. The most significant one is the $a$ axis of $\eta-\mathrm{Fe}_{2} \mathrm{C}$ (the deviation is close to $10 \%$ ) using the DFT-LDA approach.

In conclusion, the MEAM approach predicts the lattice parameters of the bcc family and fcc family members well, but for the hcp family members, there are significant deviations, possibly due to the anisotropy of layered Fe hcp sublattices.

\section{Temperature dependence of iron phases and cementite}

One advantage of the semi-empirical MEAM approach compared to DFT calculations is its ability to perform largescale molecular dynamics simulations. To investigate the performance of the potentials as a function of temperature, ferrite and austenite were used as test systems. Calculations were performed for a cell of 16000 bcc Fe atoms and 16384 fcc Fe atoms. The systems were heated step by step with a step dwell time of about $15 \mathrm{fs}$. The calculated results are shown in Fig. 3.

Disregarding entropy effects, we see that bcc Fe is more stable than fcc Fe over the whole temperature range where the systems are crystalline. The melting temperature obtained in this way is about $2200 \mathrm{~K}$ for bcc Fe. This is slightly higher than the experimental value $(1811 \mathrm{~K})$. To investigate the melting temperature of bcc $\mathrm{Fe}$ with more precision, additional molecular dynamics simulations were conducted. First, a large system containing about $50000 \mathrm{Fe}$ atoms is divided into two parts by connecting one half of the atoms to anchor points fixed in space and leaving the other half free. Next, the system is heated to $3000 \mathrm{~K}$, as a result of which the free part melts and forms a liquid. After about $100 \mathrm{fs}$, the constraints on the other half were released, and the two parts were allowed to continue adiabatically. In this phase, a thermal equilibrium is gradually reached, with a coexistence of bcc and liquid Fe. In this way, the melting temperature of bcc Fe was obtained to be $1900( \pm 80) \mathrm{K}$, close to the experimental value $(1811 \mathrm{~K})$.

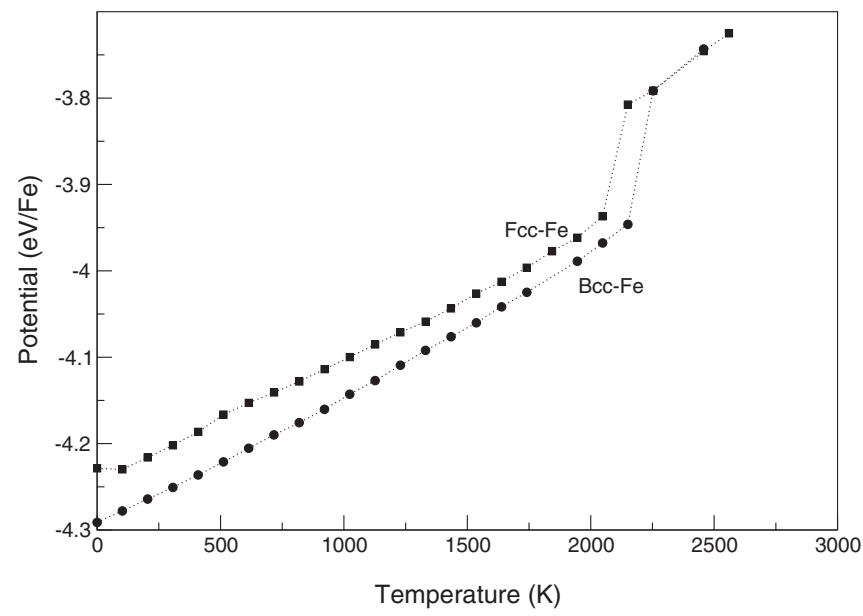

FIG. 3. The dependence of the calculated MEAM potential energy $(\mathrm{eV} / \mathrm{Fe})$ on temperature for bcc Fe and fcc Fe.

From Fig. 3, it is clear that there is no austenite window. The austenite window (1185 to $1667 \mathrm{~K}$ ) comes from the Curie-Weiss magnetism disordering effects of ferrite and austenite, ${ }^{51,59}$ while the MEAM potential does not take into account any magnetic (ordering) effects. Nonetheless, the present calculations show that the MEAM approach is capable of describing the relative stability of austenite in the temperature range $0-800 \mathrm{~K}$. This justifies the use of the MEAM potential in investigations of the stability of austenite and other phases in the treatment processes of many $\mathrm{Fe}-\mathrm{C}$ steels.

The cementite phase, $\theta-\mathrm{Fe}_{3} \mathrm{C}$ plays an important role in the tempering of steels, and it is has a pivotal role in many microstructures, such as pearlite and bainite in steels. Knowledge about thermal behavior of cementite is important to assess the reliability of molecular simulations. ${ }^{60}$ The simulations show that $\theta-\mathrm{Fe}_{3} \mathrm{C}$ remains crystalline up to a temperature of about $750 \mathrm{~K}$. The MEAM potential energy increases with temperature, being similar to that of iron phases. The MEAM lattice parameters of the orthorhombic cell increase with temperature, as well. In the temperature range from about 200 to $500 \mathrm{~K}$, the calculated linear thermal expansion parameters show a slight anisotropy: $1.4 \times 10^{-5}(1 / \mathrm{K})$ for the $a$ axis, and $1.2 \times 10^{-5}(1 / \mathrm{K})$ for the $b$ and $c$ axes. In 2004, Wood made careful measurements of thermal expansion parameters for $\theta-\mathrm{Fe}_{3} \mathrm{C} .^{61}$ They observed anisotropy of the $a$ axis from the $b$ and $c$ axes, which is in line with our MEAM calculations, on one hand. They also observed strong impacts of magnetic ordering: the volume expansion is about $1.8 \times 10^{-5}(1 / \mathrm{K})$ when $T<T c(T c=480 \mathrm{~K}$, the Curie temperature) and about $4,1 \times 10^{-5}(1 / \mathrm{K})$ when $T>T c{ }^{61}$

\section{CONCLUSIONS}

We used Lee's Fe-C MEAM potential to investigate the relative stability and structural properties of pure iron phases and iron carbides. This MEAM potential performed well in describing the lattice parameters and cohesive energies of ferrite and austenite, as well as the lattice parameters of most $\mathrm{Fe}-\mathrm{C}$ systems. Exceptions are the very high stabilities of the iron carbides having very high $\mathrm{C}$ concentrations such 
as $\alpha^{\prime \prime}-\mathrm{Fe}_{3} \mathrm{C}_{2}, \mathrm{o}-\mathrm{Fe}_{7} \mathrm{C}_{3}$, and $\eta-\mathrm{Fe}_{2} \mathrm{C}, \gamma^{\prime \prime}-\mathrm{FeC}$ ( $\mathrm{ZnS}$-type). The accuracy of the MEAM approach is at the same level as the conventional DFT-LDA approach, in particular for steels having low $\mathrm{C}$ concentrations. This is a good achievement for a non-quantum mechanical approach. From the present results, it can be concluded that Lee's MEAM potential can be applied with reasonable accuracy in molecular dynamics simulations of ferrite-austenite interfaces as well as for $\mathrm{C}$ in ferrite-austenite based systems, in particular in the temperature range up to $800 \mathrm{~K}$.

\section{ACKNOWLEDGMENTS}

This research was carried out under Project No. MC5.06280 in the framework of the Research Program of the Materials Innovation Institute M2i (www.m2i.nl), The Netherlands.
*Dr. Changming Fang, Kavli Institute of Nanoscience, Delft University of Technology, Lorentzweg 1, 2628 CJ Delft, The Netherlands; c.fang@tudelft.nl

${ }^{1}$ L. J. Hofer and E. M. Cohn, Nature 167, 977 (1951).

${ }^{2}$ D. H. Jack and K. H. Jack, Mater. Sci. Engin. 11, 1 (1973).

${ }^{3}$ H. J. Goldschmidt, J. Iron Steel Inst. 160A, 345 (1948).

${ }^{4}$ S. Nagakura and S. Oketani, Transactions ISIJ 8, 265 (1968).

${ }^{5} \mathrm{JW}$ Christian, The Theory of Transformation in Metals and Alloys (Pergamon Press, Amsterdam/Boston/London/NewYork/ Oxford/Paris/SanDiego/SanFrancisco/Singapore/Sydney/Tokyo, 2002).

${ }^{6}$ M. Taneike, F. Abe, and K. Sawada, Nature 424, 294 (2003).

${ }^{7}$ S. O. Kruijver, L. Zhao, J. Sietsma, S. E. Offerman, N. H. van Dijk, E. M. Lauridsen, L. Margulies, S. Grigull, H. F. Poulsen, and N. H. van Dijk, J. Phys. IV France 104, 499 (2003).

${ }^{8}$ S. van der Zwaag and J. Wang, Scr. Mater. 47, 169 (2002).

${ }^{9}$ V. Andrade-Carozzo and P. J. Jacques, Mater. Sci. Forum 500-501, 445 (2005).

${ }^{10}$ O. Muránsky, P. Šittner, Zrník, and E. C. Oliver, Acta Mater. 56, 3367 (2008).

${ }^{11}$ E. Jimmenez-Melero, N. H. van Dijk, L. Zhao, J. Sietsma, S. E. Offerman, J. P. Wright, and S. van der Zwaag, Acta Mater. 55, 6713 (2007).

${ }^{12}$ G. K. Tirumalasetty, M. A. van Huis, C. M. Fang, F. D. Tichelaar, Q. Xu, D. N. Hanlon, J. Sietsema, and H. W. Zandbergen, Acta Mater. 59, 7406 (2011).

${ }^{13}$ H. Letner, M. Bishof, H. Clemens, S. Erlach, B. Sonderegger, E. Kozeschnik, J. Svoboda, and F. D. Fischer, Adv. Engin. Mater. 8, 1066 (2006).

${ }^{14}$ K. H. Lo, C. H. Shek, and J. K. L. Lai, Mater. Sci. Engin. R 65, 39 (2009).

${ }^{15}$ IR Shein, NI Medvedeva, and AL Ivanovskii, Physica B 371, 126 (2006).

${ }^{16}$ HI Faraoun, YD Zhang, C Esling, and H Aourag, J. Appl. Phys. 99, 093508 (2006).

${ }^{17}$ M. H. F. Sluiter, Phase Stability of carbides and Nitrides in Steel, Mat. Res. Soc. Proc. Vol. 979 E., edited by D. N. Seidman, P. Bellon, C. Abromeit, and J. L. Boquet, MRS Fall-meeting Boston 2006, session HH(200), paper number: 0979-HH14-03.

${ }^{18}$ C. M. Fang, M. A. van Huis, and H. W. Zandbergen, Phys. Rev. B 80, 224108 (2009).

${ }^{19}$ C. M. Fang, M. A. van Huis, M. H. F. Sluiter, and H. W. Zandbergen, Acta Mater. 58, 2968 (2010).

${ }^{20}$ C. M. Fang, M. A. van Huis, and H. W. Zandbergen, Scr. Mater. 63, 618 (2010).

${ }^{21}$ Z. Q. Lv, S. H. Sun, P. Jiang, B. Z. Wang, and W. T. Fu, Comput. Mat. Sci. 42, 692 (2008).
${ }^{22}$ J. H. Jang, I. G. Kim, and H. K. D. H. Bhadeshia, Scr. Mater. 63, 121 (2010)

${ }^{23}$ J. Y. Xie, N. X. Chen, J. Shen, L. D. Teng, and S. Seetharaman, Acta Mater. 53, 2727 (2005).

${ }^{24}$ K. O. E. Henriksson and K. Nordlund, Phys. Rev. B 79, 144107 (2009).

${ }^{25}$ M. S. Daw and M. I. Baskes, Phys. Rev. Lett. 50, 1285 (1983).

${ }^{26}$ M. S. Daw and M. I. Baskes, Phys. Rev. B 29, 6443 (1984).

${ }^{27}$ M. Ruda, D. Farkas, and G. Garcia, Comput. Mater. Sci. 45, 550 (2009).

${ }^{28}$ M. I. Mendelev, S. Han, D. J. Srolovitz, G. J. Ackland, D. Y. Sun, and M. Asta, Philos. Mag. 83, 3977 (2003).

${ }^{29}$ D. J. Hepburn and G. J. Ackland, Phys. Rev. B 78, 165115 (2008).

${ }^{30}$ Q. F. Fang and R. Wang, Phys. Rev. B 62, 9317 (2000).

${ }^{31}$ C. Bos, J. Sietsma, and B. J. Thijsse, Phys. Rev. B 73, 104117 (2006).

${ }^{32}$ M. I. Baskes, Phys. Rev. B 46, 2727 (1992).

${ }^{33}$ B. J. Lee and M. I. Baskes, Phys. Rev. B 62, 8564 (2000).

${ }^{34}$ B. J. Lee, J. H. Shim, and M. I. Baskes, Phys. Rev. B 68, 144112 (2003).

${ }^{35}$ K. Nordlund and S. L. Dudarev, C. R. Physique 9, 343 (2008).

${ }^{36}$ B. J. Lee, Acta Mater. 54, 701 (2006).

${ }^{37}$ B. J. Lee, T. H. Lee, and S. J. Kim, Acta Mater. 54, 4597 (2006).

${ }^{38}$ H. K. Kim, W. S. Jung, and B. J. Lee, Acta Mater. 57, 3140 (2009).

${ }^{39}$ B. J. Lee, JPEDAV 30, 509 (2009).

${ }^{40}$ J. W. Jang, J. Kwon, and B. J. Lee, Scr. Mater. 63, 39 (2010).

${ }^{41}$ B. J. Thijsse, "Doing Molecular Dynamics with CAMELION," Virtual Materials Lab, Department of Materials Science and Engineering, Delft University of Technology, The Netherlands, [http://web.mac.com/barend.thijsse].

${ }^{42}$ H. J. C. Berendsen, J. P. M. Postma, W. F. van Gunstere, A. Dinola, and J. R. Haak, J. Chem. Phys. 81, 3684 (1984).

${ }^{43}$ G. Kresse and J. Hafner, Phys. Rev. B 47, 558 (1993).

${ }^{44}$ G. Kresse and J. Hafner, Phys. Rev. B 49, 14251 (1994).

${ }^{45}$ G. Kresse and J. Furthmüller, Comput. Mat. Sci. 6, 15 (1996).

${ }^{46}$ P. E. Blöchl, Phys. Rev. B 50, 17953 (1994).

${ }^{47}$ G. Kresse and J. Furthmüller, Phys. Rev. B 59, 1758 (1999).

${ }^{48}$ J. P. Perdew, K. Burke, and M. Ernzerhof, Phys. Rev. Lett. 77, 3865 (1996).

${ }^{49}$ D. M. Ceperley and B. J. Alder, Phys. Rev. Lett. 45, 566 (1980).

${ }^{50}$ H. J. Monkhorst and J. D. Pack, Phys. Rev. B 13, 5188 (1976).

${ }^{51}$ C. Zener, J. Appl. Phys. 22, 372 (1955).

${ }^{52}$ H. C. Herper, E. Hoffmann, and P. Entel, Phys. Rev. B 60, 3839 (1999).

${ }^{53}$ D. W. Boukhvalov, Yu. N. Gornostyrev, M. I. Katsnelson, and A. I. Lichtenstein, Phys. Rev. Lett. 99, 247205 (2007). 
${ }^{54}$ M. van Schilfgaarde, I. A. Abrikosov, and B. Johansson, Nature (London) 400, 46 (1999).

${ }^{55}$ C. Amador, W. R. L. Lambrecht, and B. Segall, Phys. Rev. B 46, 1870 (1992).

${ }^{56}$ C. Domain and C. S. Becquart, Phys. Rev. B 65, 024103 (2001).

${ }^{57}$ GTE Unary Database version v4.4, 20 July 2001, see e.g. Elements and binary systems from $\mathrm{Ag}-\mathrm{Al}$ to $\mathrm{Au}$ to $\mathrm{Tl}$, in Thermodynamic Properties of Inorganic Materials, edited by P. Franke and D. Neuschültz, Landolt-Börnstein: New Series Group 4: Phys.
Chem. Vol 19 XXVI, Scientific Group Thermodata Europe (SGTE), (Springer, Berlin, 2002).

${ }^{58}$ C. Domain, C. S. Becquart, and J. Foct, Phys. Rev. B 69, 144112 (2004).

${ }^{59}$ C. M. Fang, M. H. F. Sluiter, M. A. van Huis, C. K. Ande, and H. W. Zandbergen, Phys. Rev. Lett. 105, 055503 (2010).

${ }^{60}$ M. Umemoto, Z. G. Liu, K. Matsuyama, and K. Tsuchiya, Scr. Mater. 45, 391 (2001).

${ }^{61}$ I. G. Wood, L. Vocïadlo, K. S. Knight, D. P. Dobson, W. G. Marshall, G. D. Price, and J. Brodholt, J. Appl. Crystall. 37, 82 (2004). 